\title{
A MULHER NOS ANOS 60: FRÁGIL OU SUBVERSIVA?
}

\author{
Andrea Quilian de Vargas ${ }^{1}$ \\ Ana Paula Fogaça Benchimol ${ }^{2}$ \\ Rosani Ketzer Umbach ${ }^{3}$
}

Resumo: Os gritos nos porões das delegacias, o pavor nos olhos dos interrogados e os choques elétricos rechearam as páginas dos livros publicados nos anos que se seguiram ao golpe militar de 64. Inserido nesse universo de obras escritas por mãos predominantemente masculinas, está Tropical sol da liberdade, de Ana Maria Machado. Publicado em 1988, o romance se distancia dos discursos panfletários, sangrentos ou jornalísticos, tão comuns na literatura dos "anos de chumbo". Nossa ideia aqui é, mergulhados na subjetividade e no fôlego linguístico de Machado, investigar a construção da personagem Lena, a protagonista da narrativa, e sua relação com o contexto da Ditadura Militar de 64. Dividida entre dois mundos, o da mulher fortalecida e o da menina problemática, Lena tenta reconstruir a própria história, repleta de fraturas, muitas delas reflexos do período da repressão.

Palavras-chave: Machado; Romance; Mulher; Ditadura.

Abstract: The screams in the basements of police stations, the fear in the eyes of the interrogated and the electric shocks filled the pages of books published in the years that followed the military coup of 64 . Entered in this universe works written by predominantly male hands, is Tropical sol da liberdade, by Ana Maria Machado. Published in 1988, the novel moves away from, so common in the literature of the "years of lead" pamphleteers, bloody or journalistic discourses. Our idea here is to investigate the construction of the character Lena, the protagonist of the novel, and its relationship with the context of the Military Dictatorship 64. Divided into two worlds, the stronger woman and the problematic girl, Lena attempts to reconstruct their own history, full of fractures, many reflections of the period of repression. Immersed in Machados's subjectivity and linguistic ability, we'll try to understand what was "being a woman" in the 60 s.

Keywords: Machado; Novel; Woman; Dictatorship.

\footnotetext{
${ }^{1}$ Doutoranda em Letras na UFSM. E-mail: andrea.quilian@hotmail.com

${ }^{2}$ Mestre em Letras pela UFSM. E-mail: apbenchimol@yahoo.com.br

${ }^{3}$ Professora do Programa de Pós-Graduação em Letras da UFSM e bolsista PQ 1D do CNPq. E-mail: rosani.umbach@ufsm.br
} 
Melhorar era isso? Ficar dividida entre dois mundos? Parecer bonitinha e boazinha no mundo lá de fora que todo mundo está vendo, feito aquelas menininhas exemplares dos velhos livros infantis, enquanto num outro mundo lá dentro a cabeça girava em modo contínuo, pensando e lembrando sem parar, [...]? (MACHADO, 2005, p. 52).

Não é equivocado considerar que os anos 60 tenham representado, não somente no Brasil, mas também em outras plagas, um período distinto, onde havia muito em que se pensar: a Guerra no Vietnã, a altura das saias, a pílula anticoncepcional, a chegada do homem à lua, as ditaduras na América Latina e, especialmente entre nós, brasileiros, o Golpe Militar de 64. O Tropicalismo subvertia, nesse contexto, alguns valores estabelecidos e revolucionava o comportamento, apostando na máxima: "não é possível uma revolução social sem uma revolução individual” (PAES, 1992, p. 80). Para a geração dos anos 60, era preciso mais do que estudar, trabalhar, namorar; era preciso viver a política, que se refletia em todas as instâncias sociais, incluindo as universidades, as empresas, a cultura de maneira geral. A contestação à forma como a vida em sociedade se afigurava veio por intermédio do teatro, da literatura, da música. E esse não foi um fenômeno brasileiro, exclusivamente. A juventude do mundo inteiro cantava os mesmos refrões, usando outras palavras, em idiomas diferentes. O estado de felicidade permanente sonhado por esses jovens era cantado por Bob Dylan, Beatles, Jimi Hendrix, mas também por Geraldo Vandré e Chico Buarque. O cinema não esteve apartado desse espírito intrépido e inovador, tendo Glauber Rocha como idealizador do Cinema Novo, vanguarda da produção cultural brasileira e defensor da máxima "idéia na cabeça e uma câmera na mão". De acordo com Heloisa Buarque de Holanda,

no Brasil o Cinema Novo é(ra) uma questão de verdade e não de fotografismo. Para nós a câmera é(ra) um olho sobre o mundo, o travelling é(ra) um instrumento de conhecimento, a montagem não é(ra) demagogia, mas pontuação do nosso ambicioso discurso sobre a realidade humana e social do Brasil" (HOLANDA, 1984, p. 39).

Os artistas do teatro também fizeram de seus palcos espaços alternativos para a experimentação, o deboche e a alegoria para atacar o sistema político instaurado. A contracultura, que teve seu nascedouro nos 
Estados Unidos, atingiu, também, a juventude brasileira dos anos 60, que encarava a cultura como arma para a sonhada transformação social e política. Com os Beats da década de 50 e os Hippies dos anos 60, jovens brasileiros compartilhavam os mesmos ideais de liberdade e de postura contestatória.

A explosão do feminismo, considerado um dos movimentos mais importantes do século $X X$, embalado pelo "caos" revolucionário do momento, foi outro marco importante no calor dos anos 60 . As mulheres deixaram seus papeis de coadjuvantes para assumirem seus lugares no elenco principal. Entretanto, essa luta não foi fácil. $O$ atraso da mulher em relação ao homem, enquanto cidadã, está comprovado nos relatos históricos. O direito ao voto, para exemplificar, foi uma luta que teve início em 1865, quando um grupo de mulheres se reuniu, em Manchester, para lutar por esse direito, tardiamente conquistado em 1925. No Brasil, as mulheres votaram pela primeira vez somente em 1933. A pílula anticoncepcional, marco compulsório da revolução sexual, lançada no mercado em 1960, serviu de apoio ao espírito libertário feminino. Para os conservadores, logicamente, representou o símbolo da promiscuidade. Prova do interesse das forças policiais em denegrir a imagem das que usavam o medicamento foi quando, num congresso da UNE em Ibiúna, os policiais mostravam caixas de anticoncepcionais para que isso provocasse a indignação da opinião pública: "A polícia acreditava que a exibição provaria à opinião pública que as moças tinham ido ao encontro preparadas para algo mais do que discutir as questões estudantis" (VENTURA, 1988, p. 35). Enxovalhar a imagem daquelas moças e de todos os participantes do evento foi a intenção da polícia, bem como a de confundir a sociedade sobre os reais motivos das manifestações.

Questões concernentes ao casamento e à sexualidade passaram a ser debatidas em mesas de bar, na década de 70, quando ler $O$ segundo sexo, de Simone de Beauvoir, passou a ser obrigatório àquelas que intentavam subverter a ordem machista estabelecida. Mas interessa-nos lembrar o fato de que a questão do "feminino", especificamente, não se encontra dissociada de um contexto bem mais abrangente: o espírito inovador da época. É como se a luta feminina fosse uma batalha contra qualquer tipo de repressão, não exclusivamente àquela restrita aos lares das senhoras bem casadas. As 
mulheres não mudaram de forma isolada, somente enquanto fêmeas contrárias aos machos, mas enquanto cidadãs que notaram que, havia muito tempo, se haviam deixado dominar pela ditadura familiar, bem anterior à política. Retomando a citação que deu início a este texto, "parecer bonitinha e boazinha no mundo lá de fora que todo mundo está vendo" deixou de ser uma bandeira defendida pelas mulheres, mas algo contra o qual se deveria lutar ou, no mínimo, algo que merecia ser questionado.

A literatura não se absteve de se fazer presente nessa luta. Ana Maria Machado publicou, em 1988, um romance cuja narrativa está centrada na personagem Lena, uma mulher que se encontrava doente psíquica e fisicamente, que retorna à casa da mãe. Em Tropical sol da liberdade, o retorno ao berço da infância, ao contato com a brisa do mar e as amendoeiras, representava mais uma tentativa de Lena em recuperar a saúde. Mulher que vivera exilada por um tempo, na França, havia atuado, mesmo que na retaguarda, contra as forças militares e políticas que tentaram limitar a atuação de quem clamava por liberdade. A proteção ao irmão Marcelo, esse sim integrante da linha de frente das manifestações, fora a maneira encontrada por Lena de participar do movimento contra a repressão. Abrigar o irmão, queimar papeis que o comprometessem, emprestar seu próprio carro para as frequentes fugas do jovem rapaz, eram as atividades da protagonista de Machado. Junto a isso, Lena exercia a profissão de jornalista. Numa primeira leitura, o espírito contestador e justiceiro parece caracterizá-la. Entretanto, na medida em que nos embrenhamos pelo "bosque da ficção" construído por Machado, percebemos a ambiguidade dessa personagem, cindida entre duas posturas: uma moderna, contrária ao perfil passivo e languido das mulheres; outra infantilizada e fragilizada.

De maneira geral, nas mais diversas sociedades e em diferentes épocas, muitas mulheres incorporaram a ideia da obediência cega aos seus pais e maridos. Aprenderam com suas mães que deveriam ser passivas e cordatas. Muitas delas até se conformaram com esse pensamento. Num artigo intitulado A ciência é masculina? É sim senhora..., Chassot afirma que, até o início do século XX, havia pouca participação feminina em alguns segmentos, sociais e científicos. 
Sobre a quase ausência de mulheres na História da Ciência, não deixa de ser significativo que, ainda nas primeiras décadas do século 20, a Ciência estava culturalmente definida como uma carreira imprópria para a mulher, da mesma maneira que, ainda na segunda metade do século 20 , se dizia quais eram as profissões de homens e quais as de mulheres. Por que, na aurora do terceiro milênio, há mais alunas em cursos de Pedagogia? Ou mais alunos em cursos de Geologia? Não continuamos ainda demarcando quais são os espaços públicos ou quais as profissões dos homens e quais das mulheres? (CHASSOT, 2004, p. 9-28).

Segundo o pesquisador, esse fato ainda estaria relacionado ao mito de Adão e Eva. Conforme o autor, a submissão feminina se dá por duas razões: primeiro, pelo fato de a mulher ter nascido de uma costela de Adão, sendo, dessa forma, uma parte do homem; segundo, por ela ter sucumbido aos apelos da serpente e ter comido o fruto proibido, o que denota fraqueza, inferioridade. Todavia, essa suposta fraqueza é contestada pela própria história que nos conta, com o auxílio da literatura, que muitas mulheres administravam sociedades inteiras enquanto seus maridos estavam nas guerras. Em O tempo e o vento, Erico Verissimo retrata a vida das mulheres gaúchas que criavam os filhos sozinhas enquanto esperavam pacientemente que seus homens voltassem para casa. Antes disso, na Idade Média, a responsabilidade pela criação dos filhos, a manutenção da casa e o plantio e colheita do alimento, por exemplo, faziam parte da rotina de muitas mulheres. No entanto, o lugar ocupado por elas temporariamente era devolvido aos homens, quando estes retornavam das batalhas. O poder, nesse sentido, era provisório e se dava somente na ausência das figuras masculinas.

No século XVIII, o Romantismo foi um período em que se deu muita visibilidade às mulheres. Contudo, segundo Costa (2002), o que parecia ser um marco, um diferencial expressivo, assinalou o reforçamento de um binômio que ainda resiste em nossas sociedades: a mulher casta e a mulher mundana. Somente era digna de ser enaltecida a mulher pura, a donzela. Aquela mulher que não renunciasse aos prazeres da carne continuava tendo reservado um espaço à margem da sociedade. A primeira era digna de ser exposta ao público, já a segunda servia apenas para ser deleitada no ambiente privado, às escondidas, ao estilo da problemática Emma Bovary, de Flaubert. 
Essa breve incursão por distintos momentos da história, onde as mulheres desempenharam diferentes papeis e eram vistas sob ângulos igualmente diferenciados, nos possibilita a análise de uma Lena que é filha de suas antepassadas: as herdeiras de Ana Terra, as seguidoras de Emma Bovary, as leitoras de Simone de Beauvoir, as tietes de Chico Buarque. Descendente de diferentes mulheres, Lena, a protagonista de Tropical sol da liberdade, oscila entre o desejo de ser independente e a necessidade de se autoafirmar e autoproteger sob as asas da mãe. Compreender essa personagem se assemelha a interpretar um caleidoscópio, com suas múltiplas nuances: mulher, esposa, filha, irmã... Sua ânsia de liberdade se mostra em diversos momentos da narrativa, como quando relata ter tido um caso quando ainda estava casada:

Ele [Alonso] sempre soubera respeitar a liberdade dela, tinha uma vez aguentado que ela ficasse um mês em outra cidade com outro namorado até passar. Era um homem muito especial, cavalo selvagem com quem ela queria galopar pelos campos sem cerca, duas gaivotas voadoras seguindo barcos de pesca, mergulhando atrás do brilho rápido dos peixes pela imensidão do mar. Foi um presente dos deuses terem se encontrado (MACHADO, 2005, p. 126).

De mulher fiel, passa a mulher mundana, senhora de seus próprios desejos. Lena também refletia sobre a relação diferenciada que mantinha com o ex-marido, relembrando um episódio em que o casal havia se separado para que ele vivesse, da mesma maneira como ela já tinha feito, uma paixão extraconjugal. Ela não deixou, contudo, de acreditar no amor que Alonso sentia por ela.

\begin{abstract}
Queria amor - e não tinha qualquer dúvida de que Alonso a amava. Só que estava também amando outra pessoa ao mesmo tempo. Quanto ia durar, ela não sabia.Como ia evoluir, também não.Mas sabia que era possível. Já lhe tinha acontecido por um tempo.Não há nada que se possa fazer, a não ser viver intensamente e ver no que vai dar. Nesse momento, só uma coisa a segurava-a certeza do amor dele, apesar da ausência. Amor tão forte que era leal, não mentia, contava tudo que tinha vontade (MACHADO, 2005, p. 125).
\end{abstract}

Lena subverte, dessa forma, a ideia de amor romântico, fazendo uma divisão bastante nítida entre o amor que transcende, cúmplice, leal, e o amor mundano, uma relação de curto prazo e calcada em relações sexuais apenas. 
Para ela, a felicidade era direito tanto de homens quanto de mulheres. Isso é perceptível quando defende o pai, que havia arrumado uma amante e resolvera sair de casa, deixando Amália, sua mãe, depois de anos de casamento e dedicação: "-Mas mamãe, ele está sendo honesto em assumir, não mentir. E tem o direito de ser feliz..." (MACHADO, 2005, p. 153).

A protagonista de Tropical sol de Liberdade, desse modo, se afasta do perfil de mulher passiva, obediente, que acredita no amor incondicional e para a vida toda. Parece se configurar como uma mulher livre de amarras que enquadraram seres femininos em moldes fechados, com características próprias e imutáveis.

Por outro lado, à medida que nos aprofundamos no universo ficcional de Lena, percebemos que uma transformação da personagem vai se afigurando aos nossos olhos, de maneira gradativa, mas constante. Um lado distinto, fragilizado e infantilizado, vai modificando a imagem dela que havíamos construído. Isso se torna mais visível após os relatos dos episódios traumáticos do período da Ditadura Militar, tão sensivelmente vividos por ela.

Seguindo por essa esteira de pensamento, a construção de Lena, que tem um corpo machucado, desestabilizado, estéril, parece estar atrelada aos sintomas apresentados pelas vítimas de eventos traumáticos, como expõe Griselda Kaufman ${ }^{4}$.

Lo traumático bajo condiciones de violencia social lleva a una pérdida de equilibrio y seguridad y a vivencias de desamparo equiparables a la desproteción e inmadurez originarias del infante humano, también a estados de obnubilación, falta de conciencia, pérdida de significaciones y de explicación de lo ocurrido.

De forma paradoxal, a mesma Lena que atuara nas manifestações, protegera o irmão Marcelo, tivera um relacionamento fora do casamento, atitudes presumíveis num sujeito independente e maduro, demonstra um comportamento infantilizado e, muitas vezes, egoísta. Vemos em Lena uma

\footnotetext{
${ }^{4}$ KAUFFMAN, G. S. Sobre violência social, trauma y memoria. Cholonautas, Instituto re Estudios Peruanos, Peru, $1988 . \quad$ Disponível em: http://www.cholonautas.edu.pe/modulo/upload/GKauffman.pdf.
} 
mulher marcada por duas importantes impossibilidades: não procriar, não escrever. Em outras palavras, a protagonista encontrava-se impedida de deixar os rastros, as marcas da sua existência. Retomando a citação de Kaufman, interessa-nos, especialmente, o trecho que se refere à volta às atitudes infantis como marcas do trauma sofrido. Ainda segundo Kaufman, em situações-limite como as vivenciadas por Lena, o sujeito perde o equilíbrio e a segurança com relação à vida, vendo-se impossibilitado de reagir. Os fatores de instabilidade externa, aqueles vivenciados, em especial, na época da Ditadura, interferem no equilíbrio interno de Lena, que não consegue, no momento, encontrar alternativas, como podemos constatar na seguinte passagem:

O futuro era cheio de limites. Não criar nem procriar. Não admira que, no presente, esbarrasse nas paredes e tivesse dificuldade de se manter de pé. Ou que ficasse mergulhando para o avesso do seu tecido, agulha tentando alinhavar tramas dispersas, procurando resgatar no passado algum ponto de apoio que lhe desse firmeza. Mesmo que fosse só para aproveitar as sobras e chegar a uma colcha de retalhos feita em casa (MACHADO, 2005, p. 50-51).

As fraturas de Lena se refletiam agudamente no seu comportamento, sendo que o retorno quase que inconsciente e mecânico à casa da mãe era só o início de uma série de atitudes que demonstrariam, posteriormente, sua fragilidade e sua instabilidade com relação à vida.

Tinha todos os lugares do mundo para fazer isso. Nem mesmo ela sabia por que escolheu a casa. Talvez quisesse colo de mãe. Mas seria surpreendente admitir isso. Não sabia pedir e a mãe não sabia dar. Mas, quando sentiu a vontade vir, veio. Tinha que significar alguma coisa. Tudo significava (MACHADO, 2005, p. 18).

A simbologia do regresso ao lar, ao ninho, ao ovo, ao casulo, metáforas para a casa de Amália, dá-nos a impressão de que Lena buscou um recomeço, nascer de novo.

(...) A saúde estava em cacos, o trabalho que ela mais queria fazer estava proibido, o homem que ela amava preferia estar com outra, o filho com quem ela sonhava se escondia por trás das curvas do infinito, as palavras de que ela necessitava fugiam e se esfumaçavam... Mas ainda havia a casa da praia, refúgio confiável, com o carinho clandestino da mãe e esse chão de infância (MACHADO, 2005, p. 249). 
Importante lembrar que a desilusão em face da realidade social pouco ou nada alegradora criou, em Lena, uma espécie de dependência insubordinada a um outro, que poderia ser Amália, a mãe, ou Alonso, o ex marido. Com relação à mãe, não é muito complexo entender o mecanismo, visto que, desde que nascemos, é nos pais que encontramos nossos superheróis e são eles, supostamente, que resolvem nossos problemas. Mesmo que o tenha feito de modo inconsciente, foi no colo da mãe que Lena buscou lidar com as frustrações que a assombravam em moto contínuo. Entretanto, ao mesmo tempo em que procurou consolo debaixo das asas maternas, Lena, mais uma vez adotando um comportamento adolescente, não admitia ser vigiada, observada, direcionada. A presença de Amália, na verdade, em alguns momentos a incomodava.

A rebeldia, em Lena, se revelava nas coisas mais triviais e corriqueiras, levando-nos a pensar que essa era a forma encontrada por ela para tentar conviver com as lembranças do tempo em que fora incapaz de lutar contra o regime autoritário que assolou o país inteiro, ou pelo menos parte dele. Como se a impotência do passado se revertesse nessa rebeldia constante no presente.

A mãe percebia, se entristecia e comentava:

Tinha horas em que Amália achava que não era possível, na certa Lena fazia isso de propósito, só para que ninguém lhe pedisse para fazer nada, de pura preguiça. No fundo, isso lhe dava um desgosto enorme, ver a filha assim tão incapaz, tão desleixada para as coisas domésticas, tão imprestável. E, ainda por cima de tudo, não admitia ser criticada, ficava logo emburrada, de mau humor, respondendo atravessado. Ou então os olhos ficavam cheios d'água, os lábios tremiam e, se a gente dissesse mais uma coisinha, era capaz de se debulhar em lágrimas (MACHADO, 2005, p. 295).

Em uma das tentativas de recorrer a métodos alternativos para recobrar a saúde, Lena foi consultar o professor Zanotti, conhecido acupunturista. Estava cheia de esperanças. No entanto, na medida em que o professor foi se mostrando um tanto autoritário e dominador, Lena foi recuando: "Você come tudo errado, só pode mesmo ficar doente - disse ele. [...] Vamos cortar essas carnes, substituir o açúcar, equilibrar essa dieta" (MACHADO, 2005, p. 58). Aquela postura arrogante reacendeu um vulcão em Lena, como 
se todas as memórias do tempo da Ditadura viessem à tona, como se aquele professor fosse a reencarnação daqueles velhos generais da época do golpe. O professor ainda enfatizou que, caso Lena não seguisse a dieta sem laticínios prescrita por ele, poderia esperar a morte. "Muito bem, escolho a morte. Viver sem comer queijo não me interessa. Boa tarde" (MACHADO, 2005, p. 60).

Claro está que o comportamento agressivo e infantilizado da personagem, entendido como reflexo indelével de um tempo incompreensível, o dos "anos de chumbo", é marca importante na criação ficcional de Ana Maria Machado. Não bastou, para a escritora, contar fatos, alinhavar dados históricos, tecer comentários políticos ou ideológicos. A questão fundamental levantada era: como seria uma história da ditadura militar contada por uma mulher? Quais os reflexos permanentes no cotidiano das mulheres que viveram aquilo tudo? O que carregam essas tantas Lenas, Marias, Joanas que, voluntária ou involuntariamente, foram partícipes dos movimentos dos anos $60 ?$

Cada um dos capítulos da obra traz uma história à parte, sem haver interdependência com os demais, configurando, desse modo, uma estratégia narrativa que rompe com os padrões tradicionais romanescos, centrados em uma trama contínua. A elaboração fragmentária do texto, uma constante na literatura dos anos 70, expressa esteticamente o dilacerado contexto de sua produção, ratificado ainda mais pela fragmentação da protagonista.

O problema de Lena era a impossibilidade de compartilhar seu mundo subterrâneo, essa parte de sua experiência de vida, sem as palavras. A maestria com que Ana Maria Machado criou essa personagem, tão cheia de limitações, é estratégia decisiva para a criação e manutenção dos laços que nos prendem à narrativa. Em Lena, encontramos características das vítimas dos regimes totalitários que possuem o corpo como um de seus alicerces, mas também o portador das marcas da violência física ou psicológica. Entre o medo, a raiva e a insegurança, Lena viu-se obrigada a deixar o país. Essa violência simbólica, a retirada de um indivíduo de deu território, deixou marcas indeléveis na personagem, marcas que tornavam o futuro algo turvo e incerto.

Num romance construído em capítulos que podem ser lidos isoladamente como fragmentos desarticulados, sem qualquer prejuízo ao entendimento, mas, ao mesmo tempo, que mantêm uma rede de significação |90| Revista Eletrônica Literatura e Autoritarismo, no 24 - julho a dezembro de 2014 - ISSN 1679-849X http://cascavel.ufsm.br/revistas/ojs-2.2.2/index.php/LA/index 
amarrada para a compreensão do conjunto da obra, compreendemos que, inseridas no contexto da Ditadura Militar de 64, a história e a cultura das mulheres, como afirma Gerda Lerner:

\begin{abstract}
Não é e não deve ser vista como subcultura. [...] As mulheres vivem sua experiência social dentro da cultura geral e, sempre que são restringidas pela repressão ou segregação patriarcal ou isolamento (que sempre possui subordinação em seu propósito), transformam essa restrição em complementaridade (defendendo a importância da função da mulher, até mesmo de sua "superioridade") e a redefinem. Deste modo, as mulheres vivem uma dualidade - como membros da cultura geral e como cúmplices da cultura das mulheres ${ }^{5}$ (LERNER, 1981, p. 52).
\end{abstract}

Nesse sentido, o romance de Machado não deve ser considerado um manifesto ou um levante feminista, de maneira isolada, porém entendido, também, como uma das tantas perspectivas dissonantes que fizeram e fazem parte da construção da história. O olhar feminino sobre os fatos é, sem dúvida, o que o diferencia da grande maioria das obras que têm como contexto a Ditadura Militar. Entretanto, conhecer o romance de Ana Maria Machado, mergulhar na história de Lena, leva-nos a enxergar os "anos de chumbo" sob outro viés, distanciado dos discursos panfletários, alegóricos ou jornalísticos, tão comuns na literatura pós-64 e que tanto agradaram os leitores vampiros, ávidos pelo sangue das cenas de tortura. Uma parte da história do país, contada por intermédio da subjetividade e do vigor linguístico de Ana Maria Machado, é o que constitui o romance Tropical sol da liberdade.

\title{
REFERÊNCIAS
}

COSTA, Cristina. A imagem da mulher. Rio de Janeiro: SENAC, 2002.

CREVELD, Martin Van. Sexo privilegiado: o fim do mito da fragilidade feminina. Trad. Ibaíma Dafonte Tavares e Marcos Maffei. Rio de Janeiro: Ediouro, 2004.

HOLANDA, Heloisa Buarque de; GONÇALVES, Marcos A. Cultura e participação nos anos 60. São Paulo, Brasiliense, 1984.

${ }^{5}$ Tradução nossa.

Revista Eletrônica Literatura e Autoritarismo: A conservação da violência - ISSN 1679-849X http://cascavel.ufsm.br/revistas/ojs-2.2.2/index.php/LA/index 
KAUFFMAN, G. S. Sobre violência social, trauma y memoria. Cholonautas, Instituto de Estudios Peruanos, Peru, 1988. Disponível em: http://www.cholonautas.edu.pe/modulo/upload/GKauffman.pdf

LERNER, Gerda. The challenge of women's history. The majority finds its past. Nova York, 1981.

MACHADO, Ana Maria. Tropical sol da liberdade. Rio de Janeiro: Nova Fronteira, 2005.

PAES, Maria Helena Simões. A década de 60. Rebeldia, contestação e repressão política. São Paulo, Ática, 1992.

VENTURA, Zuenir. 1968. O ano que não terminou. Rio de Janeiro, Nova Fronteira, 1988. 